\title{
The case for Eoarchean plate tectonics and limited early crustal volumes from integrated geologic and isotopic observations in southwest Greenland
}

\author{
ViCKIE C. BENNETT ${ }^{1 *}$ AND ALLEN NUTMAN ${ }^{2}$
}

'Research School of Earth Sciences, The Australian National University, Canberra ACT 2601

(*correspondance: vickie.bennett@anu.edu.au)

${ }^{2}$ GeoQuEST, School of Earth, Atmospheric and Life

Sciences, University of Wollongong, Australia

Continuing and fundamental questions in Earth history focus on the timing and mechanisms of early continent formation. The $>3.6 \mathrm{Ga}$ regions of southwest Greenland, collectively known as the Itsaq Gneiss Complex (IGC) are unique in their vast exposed extent $\left(>3000 \mathrm{~km}^{2}\right)$, the high degree of preservation on local scales and being the only early Archean region to preserve a $>300$ myr history of juvenile crust production. This provides the potential for tracking of mantle chemical and isotopic evolution and linking isotopic patterns with geologic variations.

The emerging picture from the IGC and from $>3.6 \mathrm{Ga}$ rocks worldwide, is that of largely near-chondritic ${ }^{176} \mathrm{Hf}$ isotopic compositions. The first-order conclusion is that limited amounts of continental crust were extracted from the mantle and preserved prior to $\sim 3.6 \mathrm{Ga}$. However, quantification of the amounts and timing of crust formation require more detailed consideration of the potential source reservoir sizes and the associated geodynamic processes on the early Earth, facilitating or hindering recycling of early formed crust.

As is the case today, vertical and horizontal tectonic modes were both likely operating on the early Earth. However, multiple lines of geologic, tectonic and metamorphic evidence from the IGC argue for some form of early mobilelid tectonics, which is increasingly hard to reconcile with model-based stagnant lid interpretation. This evidence includes the arc-like chemistry of metabasalts and peridotites, recent recognition of paired metamorphic belts with apparent geothermal gradients spanning $<500$ to $>1000^{\circ} \mathrm{C} / \mathrm{GPa}$, and the $\mathrm{U}-\mathrm{Pb}$ age patterns of crust production. The implications of early tectonic regimes for calculation of crustal volumes with a focus on linking evolution of ${ }^{176} \mathrm{Hf}$ and ${ }^{142-143} \mathrm{Nd}$ isotopic compositions to proposed modes of crust formation in the early Earth will be explored. 
This abstract is too long to be accepted for publication.

Please revise it so that it fits into the column on one page. 